Journal of Bangladesh College of Physicians and Surgeons

Vol. 28, No. 3, September 2010

\title{
Gestational Age Predicted by Femur Length in Bangladesh
}

\author{
SQ RASHID
}

\section{Summary:}

Objective: Fetal femur length is an important parameter for determining gestational age. If we use tables based on Bangladeshi population, gestational age estimation will be more accurate. This study was therefore designed to determine the gestational age by fetal femur length measurement in our country.

Methods: Healthy gravid patients with optimal dates were included in a prospective study. Fetal femur length along with other parameters was measured. A table and a graph were prepared by Polynomial regression model. Previously established nomograms were compared with it.

Results: The gestational age predicted from the femur length measurements of 1223 subjects from 13 to 40 weeks are

\section{Introduction:}

Literature is fraught with studies and tables to determine gestational age from various fetal parameters. Still we do not have tables by fitting models, for gestational age determination of Bangladeshi population. For this reason our gestational age assessment is not so accurate, especially in the third trimester when the growth trend of our fetuses is less than that of the western fetuses. Therefore if we use western charts for age determination of fetus there is significant error in gestational age estimation and the fetus may appear small for date even when it is not. For this purpose this study was conducted, to prepare nomogram of Bangladeshi population, so that we can determine the gestational age more accurately by using our own table. This is of much importance here as gestational age assessment is the most common reason for fetal ultrsonography in our country since routine scanning is not the practice here in most cases. This is probably due to socio-economic reason.

The accuracy of femoral measurement in the prediction of fetal age has been shown by various studies. ${ }^{1,2}$ That is why this parameter has been selected in this study to assess the fetal age accurately.

Address of Correspondence: Dr. Sabrina Quddus Rashid, Sonologist, MBBS (DMC), PMS (USA), DMUD, PhD, SONOLAB, Centre for Diagnostic Ultrasound, 38, Green Super Market. $1^{\text {st }}$ floor. Green Road, Dhaka 1205, Tel: 9116940 (C), 8811711 (R).

Received: 12 July, 2009

Accepted: 20 December, 2009 presented here in a tabulated form. Percentiles, mean and standard deviations were also derived. The quadratic model showed a good fit to the data. There was a gradual increase of the femur length measurements. From 13 to 27 weeks gestation, there was no clinically important difference between this and western nomograms for predicting gestational age but after 32 weeks the difference with western nomograms became significant.

Conclusion: This nomogram is special for Bangladeshi population. It will give more accurate gestational age assessment than the western tables that are still followed in our country, especially in the $3^{\text {rd }}$ trimester.

Key Words: Gestational age, femur length, Bangladesh.

(J Bangladesh Coll Phys Surg 2010; 28: 163-166)

Subjects and Methods:

This was a prospective, cross sectional study. It was carried out from December 2004 to November 2007. Structured questionnaires were filled up. Consecutive healthy gravid women were studied who met the following criteria:

Regular periods, well-defined last menstrual period (LMP), an ultrasound scan before 20 weeks which confirmed the LMP age within 10 days, no history of maternal medical, surgical or obstetric complications or malnutrition, no uterine anomaly or large fibroids and no congenital anomaly of the fetus.

The ultrasonic scans were performed by a single sonologist on one ultrasound machine, by a $3.5 \mathrm{MHz}$ curvilinear transducer. This excluded inter-observer variations. The measurements were made by electronic calipers in $\mathrm{mm}$ and the gestational age was expressed in weeks (w) with 2 standard deviations (2SD), also expressed similarly, in weeks.

The technique of measuring the femur length (FL) involves an initial determination of the lie of the fetus and locating the femur. Once the femur has been located, an attempt is made to define both ends of the calcified portion. The image is then frozen and with multidirectional electronic calipers, the calcified portion is measured. The aim is a femur which is finely outlined 
and has clear-cut ends. ${ }^{1}$ After 32 menstrual weeks the distal femoral epiphysis is visible but not included in the measurement. ${ }^{2}$

Body mass index (BMI) was used to determine the nutritional status. 18.5 was taken as the cutoff value. ${ }^{3}$ SPSS was used for data entry and analysis in the computer. Polynomial regression model was fitted to the data.

\section{Results:}

The demographic characteristics of the study population of 1223 subjects were as follows. Mean maternal age was $26.95 \pm 4.49$ (1SD) with a range of 17 to 40 years. It was predominantly a middle class population. $96.9 \%$ were from middle class, $0.8 \%$ belonged to lower class and $2.3 \%$ were from upper class.

93.6\% were from urban and 6.4\% from rural areas. $54.7 \%$ were primipara and $45.3 \%$ were multipara. Mean parity was 0.6 ( \pm 0.78$)$. Mean BMI was found to be 23.67 $( \pm 3.4)$.

The coefficient of multiple correlation, $\mathrm{R}^{2}=0.975$. The quadratic model gave a good fit to the data. Graph 1 shows raw data of fetal femur length with fitted $3^{\text {rd }}$, $10^{\text {th }}, 50^{\text {th }}, 90^{\text {th }}$ and $97^{\text {th }}$ percentiles.

In Table $1,10 \mathrm{~mm}$ predicts $13.2( \pm 0.75)$ (2SD) weeks, $45 \mathrm{~mm}$ predicts $25( \pm 2.08)$ weeks, $68 \mathrm{~mm}$ predicts 36.1 ( \pm 2.95 )weeks and $74 \mathrm{~mm}$ predicts $40( \pm 3.14$ ) weeks.

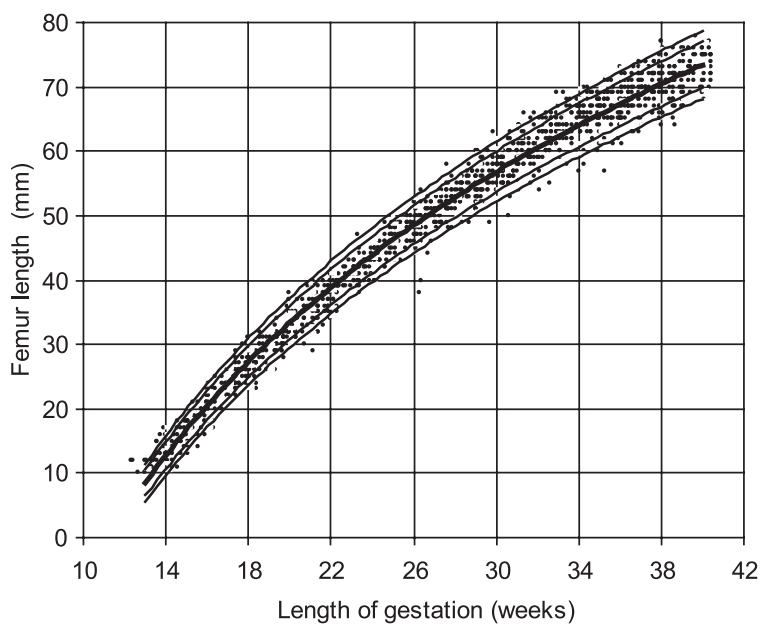

Fig.-1: Raw data of fetal Femur length with fitted $3^{\text {rd }}$, $10^{\text {th }}, 50^{\text {th }}, 90^{\text {th }}$ and $97^{\text {th }}$ centiles.
Table-I

Weeks of gestation for FL $R^{2}=0.975$

\begin{tabular}{|c|c|c|}
\hline & G. Age (w) & \\
\hline $\mathrm{FL}(\mathrm{mm})$ & Mean (w) & $2 \mathrm{SD}(\mathrm{w})$ \\
\hline 10 & 13.2 & 0.75 \\
\hline 11 & 13.5 & 0.79 \\
\hline 12 & 13.7 & 0.83 \\
\hline 13 & 14.0 & 0.87 \\
\hline 14 & 14.3 & 0.91 \\
\hline 15 & 14.5 & 0.94 \\
\hline 16 & 14.8 & 0.98 \\
\hline 17 & 15.1 & 1.02 \\
\hline 18 & 15.4 & 1.06 \\
\hline 19 & 15.6 & 1.09 \\
\hline 20 & 15.9 & 1.13 \\
\hline 21 & 16.2 & 1.17 \\
\hline 22 & 16.5 & 1.21 \\
\hline 23 & 16.8 & 1.25 \\
\hline 24 & 17.2 & 1.28 \\
\hline 25 & 17.5 & 1.32 \\
\hline 26 & 17.8 & 1.36 \\
\hline 27 & 18.1 & 1.40 \\
\hline 28 & 18.5 & 1.43 \\
\hline 29 & 18.8 & 1.47 \\
\hline 30 & 19.2 & 1.51 \\
\hline 31 & 19.5 & 1.55 \\
\hline 32 & 19.9 & 1.59 \\
\hline 33 & 20.2 & 1.62 \\
\hline 34 & 20.6 & 1.66 \\
\hline 35 & 21.0 & 1.70 \\
\hline 36 & 21.3 & 1.74 \\
\hline 37 & 21.7 & 1.78 \\
\hline 38 & 22.1 & 1.81 \\
\hline 39 & 22.5 & 1.85 \\
\hline 40 & 22.9 & 1.89 \\
\hline 41 & 23.3 & 1.93 \\
\hline 42 & 23.7 & 1.96 \\
\hline 43 & 24.1 & 2.00 \\
\hline 44 & 24.5 & 2.04 \\
\hline 45 & 25.0 & 2.08 \\
\hline 46 & 25.4 & 2.12 \\
\hline 47 & 25.8 & 2.15 \\
\hline 48 & 26.3 & 2.19 \\
\hline 49 & 26.7 & 2.23 \\
\hline
\end{tabular}

Table Continue 


\begin{tabular}{lcc} 
& G. Age $(w)$ & \\
FL $(\mathrm{mm})$ & Mean $(w)$ & 2 SD $(w)$ \\
\hline 50 & 27.2 & 2.27 \\
51 & 27.6 & 2.30 \\
52 & 28.1 & 2.34 \\
53 & 28.5 & 2.38 \\
54 & 29.0 & 2.42 \\
55 & 29.5 & 2.46 \\
56 & 30.0 & 2.49 \\
57 & 30.4 & 2.53 \\
58 & 30.9 & 2.57 \\
59 & 31.4 & 2.61 \\
60 & 31.9 & 2.64 \\
61 & 32.4 & 2.68 \\
62 & 32.9 & 2.72 \\
63 & 33.5 & 2.76 \\
64 & 34.0 & 2.80 \\
65 & 34.5 & 2.83 \\
66 & 35.0 & 2.87 \\
67 & 35.6 & 2.91 \\
68 & 36.1 & 2.95 \\
69 & 36.7 & 2.98 \\
70 & 37.2 & 3.02 \\
71 & 37.8 & 3.06 \\
72 & 38.4 & 3.10 \\
73 & 38.9 & 3.14 \\
74 & 39.5 & 3.17 \\
\hline
\end{tabular}

value of coefficient of multiple correlations shows a good relation between the two variables. The polynomial regression quadratic model showed a good fit to the data. The graph shows that there was increased dispersion of data and the fitted curves as the gestational age increased.

Previous studies on Bangladeshi population had determined that our fetal measurements were smaller than the western ones. ${ }^{5-11}$ In this study $10 \mathrm{~mm}$ predicted 13 week (2SD, $\pm 1 \mathrm{w})$ and $74 \mathrm{~mm}$ predicted 40 weeks $( \pm 3 \mathrm{w})$. Whereas in another Bangladeshi study at $16 \mathrm{w}$, femur length was $19 \mathrm{~mm}( \pm 2.6 \mathrm{~mm})(1 \mathrm{SD})$ and at 40 week it was $72 \mathrm{~mm}( \pm 3.2 \mathrm{~mm}) .{ }^{10}$

In an Indian study, at 13 week gestational age femur length was $11 \mathrm{~mm}$ and at 40 week it was $76 \mathrm{~mm} .{ }^{12}$

In Western studies, $10 \mathrm{~mm}$ predicted 13 week $( \pm 7 \mathrm{~d})$ (2SD) and $75 \mathrm{~mm}$ predicted 40 week $( \pm 23 \mathrm{~d}),{ }^{13} 10 \mathrm{~mm}$ predicted 13 week $( \pm 10 \mathrm{~d})(2 \mathrm{SD})$ and $78 \mathrm{~mm}$ predicted 40 week $( \pm 22 \mathrm{~d}){ }^{14}$ and in an early study $18 \mathrm{~mm}$ indicated $15 \mathrm{w}( \pm 6 \mathrm{~d})(2 \mathrm{SD})$ and $75 \mathrm{~mm}$ indicated 40 week $( \pm 22 \mathrm{~d})$. 15

All studies showed that in the early $2^{\text {nd }}$ trimester Bangladeshi, Indian and Western measurements were similar but as pregnancy progressed there was discrepancy between different races. The observed values of femur length measurement of other Bangladeshi studies were similar to this one. Indian and western were little bigger than Bangladeshi values.

\section{Discussion:}

Estimation of gestational age accurately is one of the most important functions of diagnostic ultrasound. Of all the parameters used to determine gestational age, femur length has been proved to be one of the most accurate, by different studies. ${ }^{1,2}$ Determination of gestational age by ultrasound has now become an integral part of maternal antenatal care. Since up to $50 \%$ of mothers who claim to know with certainty are in fact more than two weeks in error when gestational age is calculated with ultrasound. A discrepancy of 2 weeks can be critical for the survival of an infant who has to be delivered early because of some antenatal complication. ${ }^{4}$

In this study femur length was measured from 13 to 40 weeks gestational age. It was found to increase gradually with gestational age. After regression analysis of the raw data the table to predict the gestational age from femur length measurement, was prepared. The high

LIMITATION: The study population was predominantly of middle class as poor patients mostly deliver at home. Even when they go to doctors most of them are unable to recall their LMP accurately, which was necessary for this study.

\section{Conclusion:}

In 1223 subjects, from 13 to 27 weeks gestation, there was no clinically important difference between this and western nomograms but after 32 weeks the difference with western nomograms became significant. This nomogram is therefore special for Bangladeshi population and can be useful for accurate dating of pregnancies specially in the third trimester, as there was a difference of 2-3 weeks at term between this and different western charts.

Recommendation: More such studies can be done on other fetal parameters to prepare Bangladeshi charts. 


\section{References:}

1. O’Brien GD, Queenan JT, Campbell S. Assessment of gestational age in the second trimester by real-time ultrasound measurement of the femur length. Am J Obstet Gynecol 1981; 139(5): 540- 5.

2. Queenan JT, O’Brien GD, Campbell S. Ultrasound measurement of fetal limb bones. Am J Obstet Gynecol 1980; 138: 297- 302 .

3. WHO Technical Report Series. Diet, Nutrition and the prevention of chronic diseases. Report of a Joint WHO/FAO Expert consultation 2003; Vol. 916.

4. Palmer PES. Estimation of fetal size and age (Fetal biometry). Manual of diagnostic ultrasound. Geneva. WHO 1995; p 23644.

5. Moslem F, Latifa S, Iffatara B, Shamsuddin AK, Nasreen M, Momen A, et al. Relation of BPD with gestational age in Bangladeshi fetus. Bangladesh J Ultrasonogr 1996; 3: 3- 8.

6. Bala KG. Ultrasound assessment of fetal BPD during normal pregnancy in Bangladeshi women and review of literatures. Bangladesh J Ultrasonogr 1991; 1: 3.

7. Rashid SQ. A study correlating the menstrual age and fetal age by ultrasonography in Bangladeshi population. Bangladesh J Ultrasonogr 1999; 6: 3- 8.
8. Rashid SQ. Ultrasonic measurement of fetal abdominal circumference in context to Bangladeshi population. Bangladesh Med J 2000; 29: 36- 8.

9. Rashid SQ, Khatun S. A study of estimated fetal weights by ultrasound in Bangladesh and its correlation with Birth weights. J Bangladesh Coll Phys and Surg 2001; 19: 47- 51.

10. Quddus S. Fetal Biometry and Fetal weight in Bangladeshi population. Dissertation DMUD (USTC) 2002; 53- 69.

11. Rashid SQ. Gestational age estimation from fetal Head circumference in Bangladesh. 11 ${ }^{\text {th }}$ Congress of the World Federation for Ultrasound in Medicine and Biology (WFUMB), Paper presented. Ultrasound in Medicine and Biology. Clinical Obstetrics 2006; 32 (5S) 2361: 163.

12. Rajan R, Girija B, Vasantha R. Ultrasound determination of fetal growth parameters and gestational age. In: Malhotra N, Kumar P, Dasgupta S, Rajan R (eds.) Ultrasound in Obstetrics and Gynecology, $3^{\text {rd }}$ Ed. New Delhi, Jaypee Brothers 2001; 394-98.

13. Hansmann M, Hackeloer BJ, Staudach A. Ultrasound diagnosis in Obstetrics and Gynecology. Berlin. 1985; 62-70.

14. Hadlock FP, Harrist RB, Deter RL, Park SK. Fetal femur length as a predictor of menstrual age: Sonographically measured. Am J Radiology 1982; 138: 875- 8.

15. Campbell S and group. At Harris Birthright Center, King's College Hospital. 1977. 